\title{
Idea Sources of the Artemisinin Research Summary of Ge Hong's natural philosophy
}

\author{
Ling Xu \\ Nanchang institute of technology, Nangchang 330000, China \\ xuling24091818@163.com
}

Keywords: Ge Hong's natural philosophy, Artemisinin.

\begin{abstract}
Based on the successful discovery of artemisinin by Chinese female scientist Tu Youyou who won the Noble Prize in physiology or medicine and who is inspired by Ge Hong's Zhouhou Beiji Fang, this article introduces Ge Hong's natural philosophy from its ontology, epistemology and dialectics by starting with the family background, life story, historical background and theoretical background of the formation of Ge Hong's philosophical thought, and then carries on the comprehensive appraisal to its natural philosophy thought and points out its scientific contribution as well as the historical limitation ${ }^{[1]}$.
\end{abstract}

\section{Introduction}

Among the winners of the 2015 Nobel Prize in physiology or medicine, Chinese scientist Tu Youyou attracted worldwide attention by her discovery of artemisinin that can fight malaria. During the research of antimalarial effects on Artemisia annua, Tu Youyou was inspired by Ge Hong's Zhouhou Beiji Fang and then changed the extraction methods, thus successfully obtained activated artemisinin. Ge Hong established a solid foundation for the establishment of the immortal Taoism system and the outer Dan. He formed his own Taoist philosophy system in his book Bao Pu Zi which is of great importance in the history of Taoism, natural history of science and philosophy. Besides, Ge Hong is also a religionist, an ancient scientist and a rationalist theist. Many of his scientific thoughts are worth researching by later generations. Ge Hong's philosophy still has great inspiration and new research value to contemporary scientific thought.

\section{Historical background of the formation of Ge Hong's philosophical thought.}

Ge Hong grows up in a period of social unrest and belongs to the the anstocratic families in the area of Jiangdong. At the time of the social background, Jiangdong nobles had always been discriminated by Zhongyuan nobles.In addition, Ge Hong's father died when he was young. All of these factors lead to Ge Hong's hard work. Ge Hong studied classics of Confucian and Taoism since the childhood. His lifetime thoughts have always been hovering between Confucianism and Taoism and aloofness and worldliness. Ge Hong's life was filled with ups and downs and had always been hovering between aloofness and worldliness. However, the corrupt court and decadent society eventually led to Ge Hong's seclusion to Luofushan for religious, alchemy and writing, which was the main reason to form his natural philosophy. At the same time, his grandfather Ge Xuan and Zheng Yin also had a great influence of the formation of his ideas. Influenced by his grandfather Ge Xuan and his master Zheng Yin since childhood, Ge Hong showed a keen interest in religious and alchemy. From then on, Ge Hong embarked on the road of religious, self-cultivation and alchemy. When Ge Hong was young, he was influenced by his grandfather Ge Xuan and studied with Zheng Yin in his early years. When he was old, he lived in seclusion in Luofushan for religious and writing, which had a great impact on the foundation of his unique philosophical thought ${ }^{[3]}$.

\section{Theoretical background of the formation of Ge Hong's philosophical thought}

The theoretical source of philosophy mainly comes from thoughts of traditional Huang-Lao Taoism, immortal Taoism and metaphysics. Hang-Lao Taoism refers to thoughts of Yellow Emperor and Lao Tzu and its content mainly is the integration of Taoism and Legalism. It holds the idea that the King should govern by doing nothing that goes against nature in the field of social politics. In the Eastern Han Dynasty, Huang-Lao Taoism gradually combines with astrology superstition and evolves into 
the pursuit of natural longevity little by little. Ge Hong is influenced by this and has a certain effect on the formation of the original Taoism. Meanwhile, the content of immortal Taoism in Wei and Jin dynasties absorbed the main content of early Taoist Scriptures, together with the spread of pursuing immortality, which contributed to its striving development at the time of Wei and Jin dynasties. Therefore, Ge Hong made the theoretical construction of Taoism.

\section{The main contents of Ge Hong's natural philosophy thought}

Throughout all the works, discussion of ontology mainly lies in Chang Xuan and Di Zhen. Ge Hong regards mysterious, Tao and integration as the three main body theories in his own immortal Taoism system. Speaking of the relationship among those three aspects, there is a common logic and these three aspects all evolve from metaphySics to physical and from Taoist theory to astrology. They are all mixture of basic theories like natural and ontology, philosophy and religious and rationality and faith. In the field of the difference between their respective, each category has its own specific meaning and function.

The exploration of epistemology thought mainly refers to his argumentation of The Taoist theory. In epistemology, Ge Hong first inherits the naive materialism of "efficacy" of Wang Chong who uses the analogy of Zou Yan to transit to the Taoist theory. Ge Hong combines Wang Chong's experimental spirit and Zou Yan's analogy, adopts the known material as foundation and employs analogism that is from small to big and from known to unknown to form his epistemology of Taoist philosophy. Besides, he also puts forward the principle of epistemology that "the result could be tested by small testing and what is unknown could be deduced through what is known". This principle requires people to rule out mistakes caused by their senses and to believe in immortal. Only the belief in the existence of the gods could achieve the ultimate goal that ${ }^{[2]}$.

The dialectical view of Ge Hong contains many simple dialectical points of view. He proposes views on change to describe things' characteristics and the process and result of the movement and repeatedly states the relationship of mutual change and interdependence. Based on the perspective of changes in nature, Ge Hong adopts the idea of natural evolution that "everything changes" and "Tao models itself after nature" to describe his points of view that things change and develop constantly. He clarifies that the nature and the human history is in constant movement and change.

In Ge Hong's plant-based view on change, it contains both the immortal thought of Taoism and the ancient naive materialism thought. However, as for his philosophy of Taoism, the plant-based view on change is demonstrated for his supernatural being. Ge Hong believes that all substances in the world can change and he has been in the exploration of the law of the material change and way to change, and expects to create things equal to natural products. Thoughts put forward by Ge Hong in Wei and Jin dynasties laid the foundation for the later generation to know the nature and reform the nature by human practical ability.

\section{The historical position and contribution of Ge Hong's philosophy of nature}

Natural philosophy mainly contains ontology, epistemology and view of change. In the field of modern science, these concepts could find their own corresponding theories when solving issues including stating the meaning of practice, defining the concept of science, setting the goal of science, the authenticity of the cognitive object and the certainty of truth criterion.

One of the characteristics of Ge Hong's thought is to realize the incentive effect of the development of science and technology. Holding a rational attitude towards the matter of longevity, Ge Hong high lightened the importance of human action on this issue. Ge Hong realized that the key to scientific achievements is how to quickly find the correct scientific method and funny science skills. On this issue, Ge Hong adhered to the nature as the teacher and stressed the importance of nature. He thought we should learn from nature to imitate nature and create nature. Ge Hong's immortal science and science are intertwined, which contains both mysticism of religious and objective and rational scientific spirit. He explored the science based on religious theology, which is completely different from the objective of modern natural science. So, Ge Hong's scientific practice is a mixture of lots of mysticism and mystic color.

In Ge Hong's philosophy, religion and science are converging and science is mixed in Taoism. From the whole process of the development of Taoism, influenced by the teachings of the immortal 
belief, science also obtained certain development, although it presents in a kind of spontaneous form. In Taoism, the organic philosophy aimed at being immortal may play an important role in coordinating the relationship between science and religious. Meanwhile, Ge Hong also studied the elixir and clinker the elixir for the longevity. Although failed, the process of alchemy contains rich content of chemical, which plays an important role in the birth of experimental chemistry and is regarded as the pioneer of modern chemistry. Its significance and role can't be underestimated. Ge Hong's contribution in this respect is outstanding and is worth paying attention to ${ }^{[4]}$.

Pushed by the strong desire to be immortal, alchemy is also influential in medicine. Alchemists are also proficient in the pharmacology and medicine and Ge Hong is one of the famous medical experts. Ge Hong's contribution to China medicine mainly has the following aspects:

First, in order to heal the patients, Ge Hong overcame the shortcomings that ancient medical books are miscellaneous and confused. He collected the folk prescription and medical prescription, together his personal experience, and sorted out the one-hundred-volume Yuhanfang. But considering this book is too large, he imitated the style of each school's urgent prescription and then wrote the Zhouhou Beiji Fang that is both suitable for emergency and clinic.

Secondly, he summarized the inorganic pharmaceutical technology through the practice of alchemy. Gold liquid recorded in Ge Hong's Baopuzi is a great contribution in the history of chemistry as well Chinese traditional medicine. Ge Hong made a deep study in the treatment of common diseases by herbal medicine. Many of the drugs recorded in Zhouhou Beiji Fang are still effective now. Ge Hong also discusses the herbal medicine in panacea of Baopuzi. In the article of Jiyan, he emphasized that people should keep in good health and improve their resistivity and physique. It also shows the contribution of Ge Hong's views in medicine and health.

Thirdly, Ge Hong made a further research in herbal and recorded their treatment methods. In Chinese herbal medicine, Ge Hong showed particular interest in drugs. He even wrote Muzhitu and Junzhitu in Baopuzi.

So far, the evaluation of Ge Hong has located mainly in two aspects: first, he completed the immortal theory system and was regarded as the founder of Taoism; secondly, he retained some data for the history of ancient Chinese science and had his own practical experience. From Ge Hong's Bopuzi, we could dig out some innovative thoughts, which is because that the development of modern Taoism also needs innovation. From the development of theory, like some other theoretical systems, the teachings of Taoism needs to be injected new content to get a new development. According to the demand of era, some of the classic interpretation of Taoism is not enough to convince the people and even play the role of education. From the perspective of the cultural heritage of Taoism, some of our methods need to be improved. From the perspective of the survival of Taoism, the traditional way of life should be changed with the times.

Ge Hong's thought is so compelling lies in Taoism. Whether it is to examine the primitive Taoism or summarize the immortal thought, whether it is smooth or fairy, whether it is the theory on monasticism or self-cultivation, his purpose is to reform.

\section{6 . Limitations of Ge Hong's natural philosophy}

Throughout Ge Hong's works, there are lots of limitations with the features of the times and social characteristics. Ge Hong lives in a turbulent society. Although he can break the shackles of rigid ideas of Confucian, he is still an intellectual of a feudal society. His thoughts will be influenced by social class and the limitations of the times to a certain extent. Inevitably, there will be some shortcomings and mistakes on thoughts and theories.

Ge Hong believes that the cosmology of the integration of "metaphysics", "humanity" and "immortal" is the road to be immortal from people. Among the Taoism explained by Ge Hong, the most important part is how to refine immortal Taoist thought and "Xuan" is the highest among them. There are some defects and errors in the process of Ge Hong "s ontological thought, and there are some contradictions between the theory of ontology and the methodology of practical rationality.

What caused the contradiction of his theories was the wrong way of thinking to verify the immortal Taoism. But Ge Hong's limitations on epistemology and methodology further increased the 
contradiction. Ge Hong's epistemology echoes with the mystical religion. He believes that an infinite and nameless body exists in the specific and limited phenomenon world. The thought of "harmony" will deduce that it must exist an infinite world of the immortals behind the limited life world. Ge Hong's epistemology comes from mysticism ontology, while ontology contacts with the immortal world and then combines with the immortal art. This complete system serves for the Taoism theory. The illusion of Ge Hong's aim at being immortal and the fallacy of his way of thinking ultimately led to the collapse of his painstaking attainments of immortal theory system and the abrupt stop of his pursuit for being immortal.

He insisted that the property of matter is changeable so people can prolong the life span and immortal theory can also achieve that goal. Nature can reverse so life can be a long time to become immortal. This is a clear sign that in Ge Hong's view of change, the objective and final result of change serve for the immortal theory. That is both his goal and the expected result. Therefore, Ge Hong's view of change is of great thoroughness. His view of change is to promote the immortal theory and his theory that artificial change extended from plant-based change is possible. However, his conclusion that possibility of human change could infer the inevitability of the immortal theory expanded the role of the inference, which again caused the expansile error of the fact inference.

\section{Summary}

China's Wei and Jin dynasties are accompanied by a flood of philosophers with rich thoughts. Most of their thoughts cover a wide range of ideas and Ge Hong is one of the philosophers who have the distinctive feature. His works range from medicine, chemistry, philosophy, politics and literature. This thesis just chose one philosopher's thought in Wei and Jin dynasties and part of his thoughts as the object of study. The other value of the study is that the research of Ge Hong's philosophical thought could open the research of other philosophers' philosophical thought in Wei and Jin dynasties, or the further understanding and exploration of the philosophical thought during this special historical period.

This paper is the research result of the humanities and social science research project of Jiangxi Province in China, Ge Hong natural philosophy thought research (ZX1512).

\section{References}

[1] Minghui Yao, Philosophical basis and limitations of the Taoist philosophy of Ge Hong, J. Journal of Chaohu College. 8 (2008) 14-19.

[2] Sifan Li,The mind body concept and scientific cultural function of baopuzi, J.PUK. Social Sciences Research. 2 (2006) 18-22.

[3]Yikai Sun, Taoism and Chinese Philosophy, People press, Beijing,2004.

[4] Jianmin Gai,Key points of Taoist scientific ideas, Social Science Literature Press,Beijing, 2005. 